Omelyanenko V. A., PhD in Economics, Associate Professor

Omelyanenko O. M., Postgraduate Student

Sumy State Pedagogical University named after A. S. Makarenko

Sumy, Ukraine

DOI: https://doi.org/10.30525/978-9934-26-028-5-38

\title{
DIGITAL SERVICES AS A COMPONENT OF REGINAL INNOVATION SYSTEMS
}

Digitalization significantly transforms the basis of production, changes traditional ideas about the laws of economics, economic behavior, educational and scientific systems, the laws of development of social space. Digitalization forms different types of innovations, both production-technological and organizational. Digital services have great prospects in the social sphere, but at the same time, the digital economy creates not only opportunities for development, but also generates significant social risks. Finding a compromise between a robot and living human labor requires significant regulatory, fiscal, tax and other mechanisms. One of the levels at which it is possible to obtain significant benefits from digitalization and solve the related problems on the basis of multilateral cooperation is the regional one.

Regional innovation systems (RIS) have gained recently increased attention. The emphasis on regions has many reasons. Most important among them is that regional (local) innovation systems are most easily observed, since distance tends to decrease the frequency of interaction among different agents. Of significance is also the acknowledgement by researchers of the role of the regional economic milieu and geographical proximity for the innovativeness of firms.

Informal routines and norms that are specific to each region are argued to play an essential role in the behaviour of firms and the form of collaboration between them. In addition, tacit and noncodified knowledge has been recognized as of importance in the innovation process while closeness and face-to-face contacts are prerequisites for the exchange of this kind of knowledge. Focusing mainly upon national 
innovation systems (NIS), several important regional phenomena that facilitate innovation processes are ignored or not observed.

RIS have different characteristics in different regions depending on their specialization. Innovation systems in high-technology regions are, for example, most likely different from the innovation systems in traditional regions specialized in, for example, wood and metal manufacturing. Moreover, due to regional specificities, such as routines and norms mentioned earlier, RIS can also possibly be very different between regions with similar industrial structures. One is also likely to observe substantial differences in the structure and functioning of RIS between large regions with many different economic activities and in small and medium-sized regions with a less diversified economic milieu.

Recognizing that innovations stem from co-operation between many different actors, it is reasonable to question the ability of smaller regions to generate innovations. Small and medium-sized regions that often are dominated by a limited number of industries and do not host actors such as universities and research institutes are naturally disadvantaged when it comes to innovations.

Such questions are of primary concern for smaller regions as well as national governments that actively try to harmonize regional disparities in innovation capacities:

- What do RIS look like in regions that lack what is normally considered to be important actors in the innovation process?

- Can firms and communities in such regions generate innovations in spite of the absence of certain regional strategic actors and lack of competence?

- What kind of innovations can they generate and how these innovations can become successful?

Acknowledging the role of RIS makes it natural to raise a question on whether they also need special regional innovation policies to function well. Of course, there are national innovation policies but these, probably in many cases, need to be complemented with regional innovation policies focusing on regional specificities. This question is particularly relevant to small and medium-sized regions lacking the 
diversified innovation infrastructure typical of larger regions. Within these issues we can mention the OECD Analytical Report (2018) [2], which notes that digital platforms and solutions in the field of science and innovation policy (DSIP) increasingly link different sources of information and use new technologies and applications that are increasingly used for analytics innovation.

The results of research [3] suggest that Digital Innovation Hubs (DIHs) despite their emerging and trial-and-error stage are designed for promoting multi-actor collaborative platforms including non-local actors to stimulate transition into Industry 4.0 by promoting placebased collaboration alliances that respond to local/regional contextual specificities and demands. These regional-based platforms facilitate public-private partnerships that co-design policy initiatives resulting from co-participation and negotiation of spatially-bounded oriented initiatives for digitizing.

Industry 4.0 or digitization, from a RIS and policy perspective to improve regional innovation, is over-looked. Specifically, this paper aims to focus on analyzing the nascent European Commission digital innovation hub (DIH) program, designed for fostering transition into Industry 4.0 in regions and facilitating new path development. A policy debate on the European level also means learning from local experiences. Highly innovative regions in various countries provide better welfare to their citizens, better services and greater opportunities to foster innovative processes [4, p. 29].

E.g., Navarra Region DIH started in 2016 with the name of «NAVARDMIHub». With the support of the regional government in 2020, the DIH has evolved to «IRIS: European Digital Innovation Hub Navarra». The DIH aims to exploit the synergies and capabilities already organized in the regional innovation ecosystem, in terms of partners and capabilities promoting innovation, technology transfer, business creation, testing and experimentation, and training and dissemination for the digitalization [5].

Services provided by the Hub that summarizes their activities are the following: 
Service 1: Tailored training and talent: development of technology profiles to drive the digital transformation of businesses (access to degrees, masters and doctoral programmes; data science laboratory; etc.); internationalisation of talent related to digital transformation; scheme to attract international talent.

Service 2: Consultancy: awareness raising and skills development; intervention by designing pathways and technology pathways for digitalization.

Service 3: R\&D. Knowledge transfer: development of new products and processes; collection of information on your processes and production environment.

Service 4: Experimental validation of the application of new technologies to products and processes.

Service 5: Exchange of Good Practices: access to the technologies available in the European Network of Digital Innovation Hubs and it is also a space to share experience and ideas.

Service 6: Entrepreneurship: complete accompaniment program, facilitating the creation of new companies and the differentiation and drive of new projects.

Service 7: Access to funding: private and public funding / regional, national and international funding.

Based on analyzed experience within the framework of practical implementation of the Quintuple Helix model, we propose to consider the project of the creation of a regional technology transfer network.

Within the project «Innovative component of security of sustainable development of old industrial regions of Ukraine» we propose the establishing an innovation hub methodology designed to ensure communication and coordination of the regional economy's subsystems and external environment to achieve its strategic goals. The network will carry broad interdisciplinary themes, which will be formed according to the development priorities and the authorities' participation. The main activities of the network will be:

1. Transfer of technology:

- use of methodologies such as Smart Up in the incubation of hightech companies, venture capital projects offering the following model 
of cooperation: remuneration only after attracting investment in the project, the direction of the project on the attractive markets, preservation of capital, attracting cheap or "free" investments in the form of grants, SWOT-analysis of project, measures to strengthen the weaknesses of the project, development of geo-card possible further development of the project (potential investors, project scopes);

- creation of e-portal of remote scientific advice is a cooperation of innovative business, which will differ from existing analogs;

- creation of Fabrication Laboratory for high-tech projects;

2. Ecological and economic problems: we propose to use the methodology perfomens-contract based on innovative energy efficiency technologies, based on the provision of services in the complex practical energy-saving center with reimbursement of their costs and financial gain from the actual effect of activities. At the same time, public authorities, depending on the agreement, will serve the customer or guarantor.

In further studies, it is necessary to develop a design structure for such a center for a specific region, taking into account the tasks and potential of a specific RIS.

\section{References:}

1. Andersson M., Karlsson C. (2006) Regional Innovation Systems in Small and Medium-Sized Regions. In: Johansson B., Karlsson C., Stough R. (eds). The Emerging Digital Economy. Advances in Spatial Science. Springer, Berlin, Heidelberg. DOI: https://doi.org/10.1007/3-540-34488-8_4.

2. OECD (2018). OECD Science, Technology and Innovation Outlook 2018. OECD Publishing. DOI: https://doi.org/10.1787/sti_in_outlook-2018-en.

3. Hervas-Oliver J.-L., Gonzalez-Alcaide G., Rojas-Alvarado R., Monto-Mompo S. (2020) Emerging regional innovation policies for industry 4.0: analyzing the digital innovation hub program in European regions. Competitiveness Review, vol. 31, no. 1, pp. 106-129. DOI: https://doi.org/10.1108/CR-12-2019-0159.

4. Andersson L.F., Alaja A., Buhr D., Fink Ph., Stöber N. (2017) Policies for Innovation in Times of Digitalization A comparative report on innovation policies in Finland, Sweden and Germany. URL: https:/www.researchgate.net/profile/ Daniel_Buhr2/publication/309535959_Policies_for_Innovation_in_Times_of_Digitali zation_A_comparative_report_on_innovation_policies_in_Finland_Sweden_-A-comparative-report-on-innovation-policies-in-Finland-Sweden-and-Germany.pdf.

5. IRIS: European Digital Innovation Hub Navarra. URL: https://s3platform.jrc.ec.europa.eu/digital-innovation-hubs-tool/-/dih/1327/view. 